\title{
Reservas indias, venganzas sureñas y herencias familiares: el lenguaje de los cómics criminales de Jason Aaron y sus traducciones
}

\author{
Miguel Sanz Jiménez \\ Departamento de Filología Inglesa II de la Universidad Complutense de Madrid
}

Miguel Sanz Jiménez se graduó en Estudios Ingleses en la Universidad Complutense de Madrid (UCM), donde obtuvo el Premio Extraordinario de Grado. Recibió una beca para estudiar Literatura Contemporánea de Estados Unidos en la Universidad Loyola de Chicago y fue auxiliar de conversación en West Liberty, Iowa, como parte del programa del Ministerio de Educación, Cultura y Deporte. Además, dio clases de Inglés como lengua extranjera a adultos en Muscatine Community College. En España, continuó los estudios de posgrado, fue becario de la Facultad de Filología de la UCM y cursó el máster de Traducción Literaria. Su tesis doctoral trata de las implicaciones ideológicas de las estrategias traductoras en las narraciones de esclavos de Estados Unidos. Es investigador predoctoral del departamento de Filología Inglesa II de la UCM (FPU2015). Ha traducido artículos para revistas, relatos, cómics y subtítulos.

Fecha de recepción: 1 de noviembre de 2016

Fecha de aceptación definitiva: 6 de noviembre de 2016 


\title{
Resumen
}

El objetivo de este artículo, que se inscribe en el campo de los Estudios Descriptivos de Traducción, es el análisis lingüístico de los cómics escritos por el guionista Jason Aaron que se inscriben en el género negro, así como de sus correspondientes traducciones al castellano. Estos cómics son Scalped, Paletos cabrones y La herencia de la ira. Se presta atención a las influencias y motivos de la obra de Aaron, la traducción de las onomatopeyas, la intertextualidad, los títulos y el habla dialectal.

Palabras clave: Cómic estadounidense, estudios de traducción, género negro, Jason Aaron, traducción de cómics

\begin{abstract}
This paper belongs to the field of Descriptive Translation Studies. Its aim is to analyze noir comic-books written by Jason Aaron, as well as their respective Spanish translations. These comics are Scalped, Southern Bastards and Men of Wrath. Some of the features to be studied are Aaron's books' influences and motifs, the translation of sound words, intertextuality, titles, and dialect.
\end{abstract}

Keywords: American comic-books, Comics in Translation, Jason Aaron, noir comics, Translation Studies.

\section{Cita bibliográfica}

SAnz JimÉnEZ, M. «Reservas indias, venganzas sureñas y herencias familiares: El lenguaje de los cómics criminales de Jason Aaron y sus traducciones», en CuCo, Cuadernos de cómic, n. ${ }^{o} 7$ (2016), pp. 8-34. 


\section{Introducción}

El presente artículo se enmarca en el campo de los Estudios Descriptivos de Traducción (EDT), los cuales examinan las traducciones como los hechos de la cultura en la que se originan en lugar de interesarse por los errores de traducción o los estándares de calidad. Así, los EDT analizan las traducciones como los productos concretos de las normas y las convenciones de la cultura meta.

El corpus de estudio se compone de los tres cómics del guionista estadounidense Jason Aaron que pertenecen al género negro o criminal, también conocido como negrocriminal, que son Scalped, ${ }^{1}$ Paletos cabrones ${ }^{2}$ y La herencia de la ira. ${ }^{3}$ Sus respectivas traducciones al español (dos en el caso de Scalped, por lo que se trata de un caso de retraducción, como se verá más adelante) forman, asimismo, parte de este corpus.

El objetivo principal es analizar las particularidades del lenguaje de estos tres cómics y las normas que condicionan sus traducciones. Antes de ello, se observarán los motivos recurrentes de las obras de Aaron, sus influencias y contextos. A continuación, el estudio de los textos y sus traducciones se dividirá en cuatro apartados, correspondientes a la traducción de las onomatopeyas y los textos que figuran en los dibujos de las viñetas, la intertextualidad, los títulos de las obras y la problemática del habla dialectal de algunos de los personajes.

Puesto que se trata de un estudio preliminar que abrirá líneas de investigación futuras, el corpus se limita al primer volumen de cada uno de estos tres cómics, con sus correspondientes traducciones en castellano.

\section{Las obras negrocriminales de Jason Aaron}

Uno de los guionistas más prolíficos del panorama actual del cómic estadounidense es Jason Aaron (Jasper, Alabama, 1973). Empezó su carrera en 2007 con The Other Side (que en España publicó Planeta en 2009 con el título El otro bando), una miniserie con Cameron Stewart a los lápices que reflexiona acerca de la guerra de Vietnam desde los puntos de vista

\footnotetext{
1 Aaron, J. y Guéra, R. M. Scalped, n. o 1-5. Nueva York, DC Comics, 2007.

2 Aaron, J. y Latour, J. Southern Bastards: Here Was a Man. Berkeley, CA, Image Comics, 2014.

3 Aaron, J.y Garney, R. Men of Wrath, n.o 1-5. Nueva York, Marvel Comics, 2014.
} 
opuestos de Bill Everette y Vo Dai, un soldado estadounidense y otro vietnamita, respectivamente. Desde entonces, ha pasado a ocuparse de la plana mayor del universo Marvel, donde ha escrito, entre otras, las series Lobezno, Lobezno y la Patrulla X, Pecado original, una larga y aclamada etapa en Thor: Dios del trueno (que incluye el cambio de género del dios nórdico protagonista), la nueva y actualizada serie regular de Doctor Extraño y el regreso de Star Wars a Marvel, cuyo primer número batió los récords de venta ${ }^{4}$ en su lanzamiento de enero de 2015. Sin embargo, el objeto de estudio de este artículo es el trabajo de Aaron en el circuito independiente, aquellos cómics cuyos derechos son propiedad de los autores y no de la editorial, caso de Scalped, Paletos cabrones y La herencia de la ira, series que pertenecen al género negro y que comparten rasgos estilísticos y temáticos.

El primero de ellos, Scalped, narra el regreso de Dashiell Caballo Terco, un joven nativo americano, al lugar donde nació, la reserva Prairie Rose de los indios lakota en Dakota del Sur. Una vez allí, se alista en la policía tribal del jefe Lincoln Cuervo Rojo, un antiguo activista reconvertido en señor del crimen organizado que está a punto de abrir un casino que insuflará nueva vida a la reserva. La llegada de Dashiell y su reencuentro con viejos activistas, como su madre Gina y Catcher, y con Carol Ellroy, su amor de juventud, desatan una serie de conflictos violentos, pues, en realidad, Caballo Terco es un agente encubierto del FBI que viene a acabar con el imperio criminal de Cuervo Rojo.

Scalped es la primera serie regular de Jason Aaron, que comenzó a publicar en el sello Vertigo de DC en 2007 junto al dibujante serbio R. M. Guéra. Como señala Peters, ${ }^{5}$ en los sesenta números de este cómic abundan «los personajes complejos, el humor negro y una trama de agentes dobles que atrapa a los lectores». Su retrato del condado más pobre y de mayor tasa de alcoholismo de Estados Unidos, la reserva Prairie Rose, mezcla el género negro y el wéstern crepuscular para reflexionar acerca de la identidad individual, social y racial, el sentido de pertenencia, la familia, la violencia inherente a la condición humana y la herencia, temas que vertebrarán los cómics de Aaron que se contemplan en este estudio. Estos motivos recurrentes apuntan a los principales referentes literarios del guionista de Alabama en la configuración de Scalped, que son las novelas Cosecha roja, ${ }^{6}$ de Dashiell Hammett, y Meridiano de sangre, ${ }^{7}$ de Cormac McCarthy.

La primera de ellas, publicada originalmente por entregas en la revista Black Mask entre 1927 y 1928, es uno de los textos fundacionales del género negro estadounidense ${ }^{8}$ (también

${ }^{4}$ Cfr. Gonzales, D. «Star Wars \#1 Is Already 2015's Top Selling Comic», en Forbes, 13 enero 2015. Disponible en https://goo.g1/XXvQAd.

5 Peters, M. «From Scalped to Thief of Thieves: The most engrossing crime comics in history», en Salon, 3 agosto 2014. Disponible en https://goo.gl/xRlfx0.

${ }^{6}$ Hammett, D. Cosecha roja, trad. F. Calleja. Madrid, Alianza, 1994.

${ }^{7}$ McCarthy, C. Blood Meridian, or the Evening Redness in the West. Londres, Picador, 2010.

8 Cfr. Horsley, L. «American Hard-Boiled Crime Fiction», en Crimeculture, 2002. Disponible en https:// goo.g1/mXF6rC. 
conocido como hard-boiled) junto a El balcón maltés (1929), del propio Hammett, y, posteriormente, El sueño eterno (1939), de Raymond Chandler. Cosecha roja narra uno de los casos de un detective privado de dudosa moral, al que solo se le conoce por el nombre de «El agente de la Continental» en referencia a la agencia para la que trabaja y que protagonizaría una serie posterior de relatos breves. En esta ocasión, el detective viaja a la pequeña ciudad industrial californiana de Personville, apodada Poisonville, con el objetivo de mediar entre las mafias rivales que luchan por el control de la ciudad y el corrupto departamento de policía. El tono descreído de la novela, la historia coral, su retrato de la corrupción y las ansias de poder en el seno de la sociedad estadounidense, así como el doble juego del violento protagonista, quedan reflejados en el entorno por el que se desenvuelve el protagonista de Scalped, Dashiell, quien comparte nombre de pila con el autor de Cosecha roja.

Por otra parte, la novela de McCarthy antes mentada, Meridiano de sangre, recrea la expedición, a mediados del siglo XIX, de un grupo de renegados que recorre la frontera entre el sur de Texas y México para acabar con los indios y los hispanos que la habitan. El texto, que alude formalmente al Moby Dick de Herman Melville, subvierte las convenciones del wéstern como género fundacional y retrata de manera explícita la violencia de las narraciones de frontera. Las ansias por destruir y matar al otro quedan señaladas como una de las características inherentes del ser humano en una de las citas que abren la novela, que pertenece a un recorte del periódico The Yuma Daily Sun, fechado el 13 de junio de 1982, en el que se habla del descubrimiento, en el norte de Etiopía, de un cráneo humano de unos trescientos mil años de antigüedad al que le habían arrancado la cabellera. ${ }^{9}$ De ahí la conexión con el cómic de Aaron, cuyo título, Scalped, hace referencia a esta práctica, comúnmente asociada a los nativos norteamericanos.

Tras la publicación del último número de Scalped en 2012, Aaron se dedicó a su trabajo en Marvel y puso en marcha otro proyecto independiente junto al dibujante Jason Latour, titulado Paletos cabrones, ${ }^{10}$ que comenzó a publicar la editorial Image en mayo de 2014 y se ha unido al conjunto de los títulos de esta casa aclamados por los lectores y premiados por la crítica, entre los que figuran Saga, Pretty Deadly y la reciente Paper Girls, ${ }^{11}$ entre otros. Al comienzo del cómic, los lectores conocen a Earl Tubb, un veterano de la guerra de Vietnam que ha de encargarse de gestionar la finca de su familia y vuelve a su pueblo natal, el Condado de Craw, en Alabama. Cuarenta años después de que se marchara, Tubb es testigo de cómo ha degenerado su pueblo, que ahora es un nido de pobreza, alcoholismo y corrupción gobernado por el entrenador Boss, predicador de la religión local, el fútbol americano. Si bien intenta mantenerse al margen de toda la actividad del lugar, los recuerdos de su padre, antiguo sheriff, y su sentido de la justicia obligan a Tubb a inmiscuirse en los asuntos locales, lo cual desata una confrontación sangrienta contra el entrenador y sus seguidores.

${ }_{9}$ McCARThY, C. Op. cit., p. iii.

${ }^{10}$ El título original es Southern Bastards. Para una reflexión acerca de la traducción de los títulos, véase el apartado 3.3 del presente artículo.

${ }^{11} C f r$. Raferty, B. «Paper Girls is the perfect comic for your '80s nostalgia trip», en Wired, 10 mayo 2016. Disponible en https://www.wired.com/2016/10/paper-girls-must-read/. 
La presencia de McCarthy y Meridiano de sangre también puede apreciarse en las escenas de violencia cruda que se suceden en Paletos cabrones, si bien cobra protagonismo la influencia del llamado gótico sureño gracias a varias alusiones a los textos de William Faulkner y Flannery O'Connor. Son varias las referencias a El ruido y la furia, ${ }^{12}$ pues a la aparición de los miembros de la familia Compson, que en el cómic son los propietarios del banco y de la agencia inmobiliaria local, hay que sumar el retrato de la degradación y decadencia de la sociedad sureña, cuya antigua aristocracia se ha desvanecido por completo en un escenario ficticio, pues el Condado de Craw no tiene un referente real, como tampoco lo tenía el de Yoknapatawpha del canon faulkneriano. Por otra parte, los modales de los violentos habitantes recuerdan a la brutalidad del relato «Un hombre bueno es difícil de encontrar», de O'Connor, ${ }^{13}$ y su abrupto final. Paletos cabrones es también una historia coral que recoge las voces de los lugareños, sus ansiedades y conexiones con el imperio criminal que ha establecido el entrenador Boss en torno al fútbol americano. La elección de este deporte tampoco es casual y, de forma análoga a como sucedía con el béisbol en La gran novela americana, de Philip Roth, ${ }^{14}$ permite retratar la aspiración de ascenso social propia del sueño americano en términos propios de una competición deportiva que llega a enfrentar a los miembros del equipo entre sí.

En comparación con Scalped y Paletos cabrones, La herencia de la ira es un cómic menor dentro de la producción de Jason Aaron, tanto por su extensión como por su trasfondo. La narración comienza en 1903, cuando una disputa trivial entre dos ganaderos de Alabama desemboca en un asesinato. Isom Rath apuñala en el cuello a su vecino Erastus, crimen que presencia el joven Alford Rath, que quedará traumatizado de por vida. Este asesinato inicia un legado sangriento que dura hasta principios del siglo xxi cuando Ira Rath, un viejo asesino a sueldo que vive aislado en las ruinas de la granja de su familia, recibe un último encargo, que no es otro que matar a Ruben, el hijo que desapareció de su vida hace años mientras luchaba por escapar del legado de violencia que le perseguía. Esta miniserie de cinco números fue publicada entre octubre de 2014 y febrero de 2015 por el sello Icon de Marvel, que permite que los autores conserven los derechos de sus creaciones, y fue ilustrada por Ron Garney, compañero de Aaron en su etapa al frente de Lobezno. Como cuenta el guionista en el prólogo, ${ }^{15}$ el detonante de La herencia de la ira está inspirado en el crimen real que cometió su tatarabuelo. Su retrato de un entorno rural poblado por protagonistas amorales bebe de la premisa de Paletos cabrones, si bien acentúa la influencia de Meridiano de sangre al reflexionar acerca de cómo resulta inevitable escapar de la violencia que desatan los seres humanos, en este caso los miembros de la familia Rath.

Estos tres cómics aúnan costumbrismo y género negro, retratan la herencia del pasado, el regreso a casa, y la imposibilidad de huir de una naturaleza violenta. El lenguaje de estas obras define la identidad cultural, racial y social de los personajes y es un elemento clave

\footnotetext{
12 Faulkner, W. The Sound and the Fury. Londres, Vintage, 1995.

13 O’Connor, F. Cuentos completos, trad. M. Covián et al. Barcelona, Lumen, 2005.

${ }^{14}$ Roth, P. La gran novela americana, trad. D. Paradela López. Barcelona, Contraediciones, 2015.

15 Aaron, J. y Garney, R. Op. cit., p. 26.
} 
en la configuración de los ambientes en los que transcurre la acción, como se verá en el siguiente apartado. Por este motivo, presenta una serie de dificultades específicas a la hora de traducirlo al español que puede conllevar la pérdida de ciertos matices, caso de las referencias intertextuales y de las marcas dialectales en el habla. En la próxima sección se prestará atención a estos problemas de índole traductológica, así como a las soluciones y estrategias de las traducciones publicadas.

\section{Cómic en traducción}

En su trabajo acerca de la equivalencia en traducción, Rabadán dedica un capítulo a la traducción del cómic, ${ }^{16}$ titulado «El cómic y la historieta». En él, señala que la traducción de cómics es un caso de traducción subordinada, al igual que la audiovisual, pues el texto en la lengua de llegada depende de las limitaciones del medio, que en este caso son las dos siguientes: las limitaciones físicas, que se corresponden con el espacio de los bocadillos y los cuadros de texto; y las limitaciones técnicas y lingüísticas, que tienen que ver con el reemplazo de las onomatopeyas y otros insertos gráficos que están presentes en los dibujos originales, caso de los textos que figuran en carteles, periódicos, libros, etc. Esta autora explica cómo las onomatopeyas se han lexicalizado en inglés; por ejemplo, roar! ilustra el rugido de un león, si bien también es la palabra que semánticamente recoge el significado de «rugido», por lo que se subraya la dificultad de traducir las onomatopeyas al español, que suelen derivar en préstamos de la lengua original que terminan por asimilarse en el lenguaje del cómic. Rabadán, además, contempla la posibilidad de recurrir a apéndices explicativos o notas al pie para aquellos fragmentos que presenten dificultades insalvables debido a las restricciones de espacio. Respecto a la traducción de las onomatopeyas, resulta oportuno señalar el trabajo de Gubern y Gasca, quienes estudian en detalle el fenómeno arriba indicado en su Diccionario de onomatopeyas del cómic. ${ }^{17}$

Volviendo a la obra de Aaron, las traducciones al español de Paletos cabrones y de La herencia de la ira son obra de Víctor Manuel García de Isusi ${ }^{18}$ y de Gonzalo Quesada, ${ }^{19}$ respectivamente. Sin embargo, en el caso de Scalped existen dos traducciones distintas publicadas. La primera de ellas es de Bittor García ${ }^{20}$ y se corresponde a los tomos recopilatorios que comenzó a editar Planeta en 2008 hasta la conclusión de la serie, mientras que la segunda, obra de Guillermo Ruiz Carreras, ${ }^{21}$ es la nueva versión castellana de Scalped, la publicada por E1

16 RabadÁn, R. Equivalencia y traducción: Problemática de la equivalencia translémica inglés-español. León, Universidad de León, 1991, pp. 154-155.

17 Gubern, R. y Gasca, L. Diccionario de onomatopeyas del cómic. Madrid, Cátedra, 2008.

18 Aaron, J.y Latour, J. Paletos cabrones: Aqui yace un hombre, trad. V. M. García de Isusi. Barcelona, Planeta, 2016.

19 Aaron, J. y Garney, R. La herencia de la ira, trad. G. Quesada. Gerona, Panini Cómics, 2016.

20 Aaron, J. y Guéra, R. M. Scalped: Nación india, trad. B. García. Barcelona, Planeta, 2008.

${ }^{21}$ Aaron, J. y Guéra, R. M. Scalped: Libro uno, trad. G. Ruiz Carreras. Barcelona, El Catálogo del Cómic Ediciones, 2016. 
Catálogo del Cómic en la edición de cinco volúmenes de lujo que empezó a publicarse en mayo de 2016. Se trata, pues, de un ejemplo de retraducción, que Zaro Vera define como la «traducción total o parcial de un texto traducido previamente», ${ }^{22}$ que no solo incluiría a los textos traducidos de una lengua a otra, sino «a los traducidos a la misma lengua más de una vez». ${ }^{23}$ Este traductólogo explica cómo las retraducciones «proporcionan modelos adicionales que permiten el contraste, la comparación y el cuestionamiento de las decisiones tomadas en traducciones previas», ${ }^{24}$ a lo que Ortiz Gozalo añade que «retraducir es en suma una necesidad engendrada por el hecho de que la traducción perfecta es inaccesible». ${ }^{25}$ Dado que en el caso de Scalped solo han transcurrido ocho años entre una traducción y otra, es complicado que la retraducción del cómic original se deba a un cambio en los hábitos de lectura o a un lenguaje desfasado y mejor conocimiento de la lengua de origen. Sencillamente, el cambio de editorial española (de Planeta a El Catálogo del Cómic) puede conllevar la no renovación de los derechos de explotación de la primera traducción, la de 2008, lo cual explicaría la decisión de volver a traducirla en un período de tiempo tan breve.

A continuación, dentro de este apartado se van a observar las estrategias que se han empleado para traducir ciertos elementos característicos de los cómics de género negro de Jason Aaron, como son las onomatopeyas, la intertextualidad, los títulos y el habla dialectal. Con el fin de que el volumen del corpus de estudio sea equitativo, se han analizado las traducciones del primer volumen de cada una de las series, como ya se explicara en la introducción.

\subsection{Onomatopeyas e insertos}

Como señalaba Rabadán en el capítulo dedicado a la traducción del cómic, ${ }^{26}$ la traducción de las onomatopeyas y los insertos gráficos se enmarcaría dentro de las limitaciones técnicas y lingüísticas a las que hace frente el traductor. Ambas versiones de Scalped comparten el criterio de no traducir las onomatopeyas, que reproducen las expresiones del original. De este modo, en las dos traducciones coinciden los golpes (thud!), los disparos (ktow!) y las bofetadas (stuph!), si bien resulta curioso que se les añada el signo de exclamación de apertura en la versión de Ruiz Carreras, como se observa a continuación en las FIG. 1 y 2.

En cuanto a los insertos, la edición de 2016 los reproduce en castellano, reemplaza el texto de los dibujos originales por las traducciones de Ruiz Carreras, ya se trate de carteles

${ }^{22}$ Zaro Vera, J. J. «En torno al concepto de retraducción», en Zaro Vera, J. J. y Ruiz Noguera, F. (eds.). Retraducir: una nueva mirada. La retraducción de textos literarios y audiovisuales. Málaga, Miguel Gómez, 2007, p. 31 .

23 Idem.

24 Idem.

25 Ortiz Gozalo, J. M. «La retraducción en el panorama de la literatura contemporánea», en Zaro Vera, J. J. y Ruiz Noguera, F. (eds.). Retraducir: una nueva mirada. La retraducción de textos literarios y audiovisuales. Málaga, Miguel Gómez, 2007, p. 35.

${ }^{26}$ Rabadán, R. Op. cit., p. 154. 


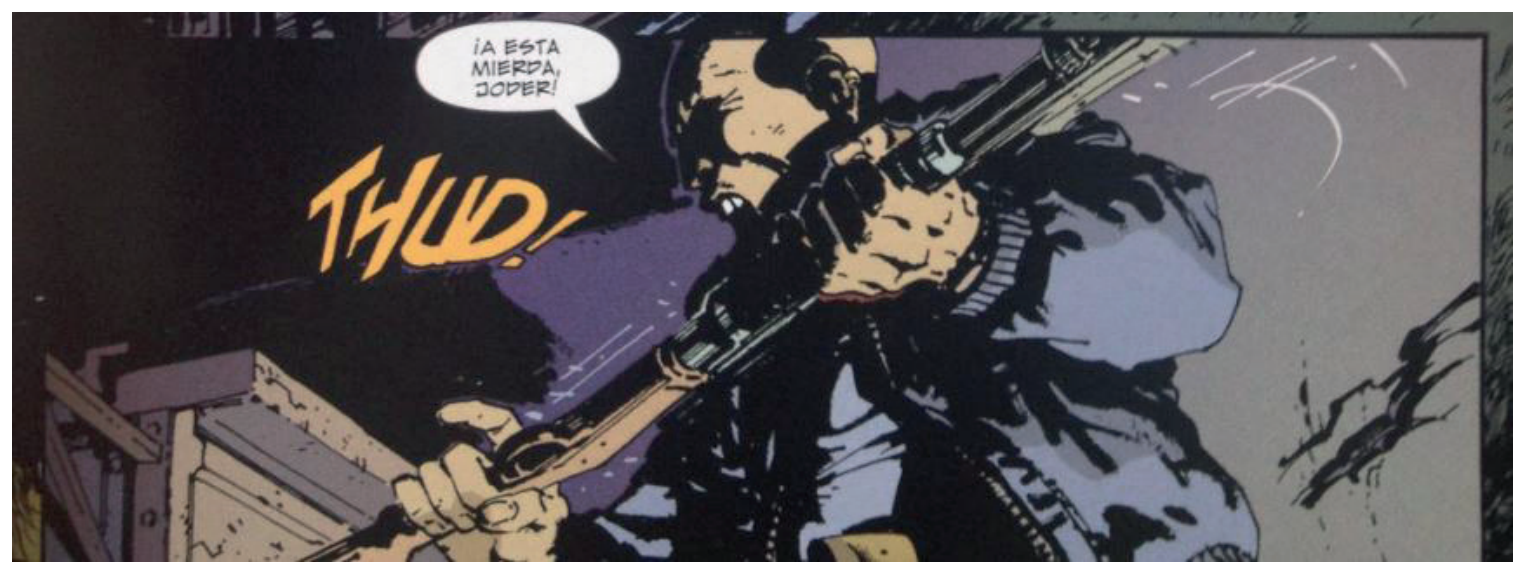

FIG. 1. Aaron, J. y Guéra, R. M. Scalped: Nación india, trad. B. García. Barcelona, Planeta, 2008 , p. 29.

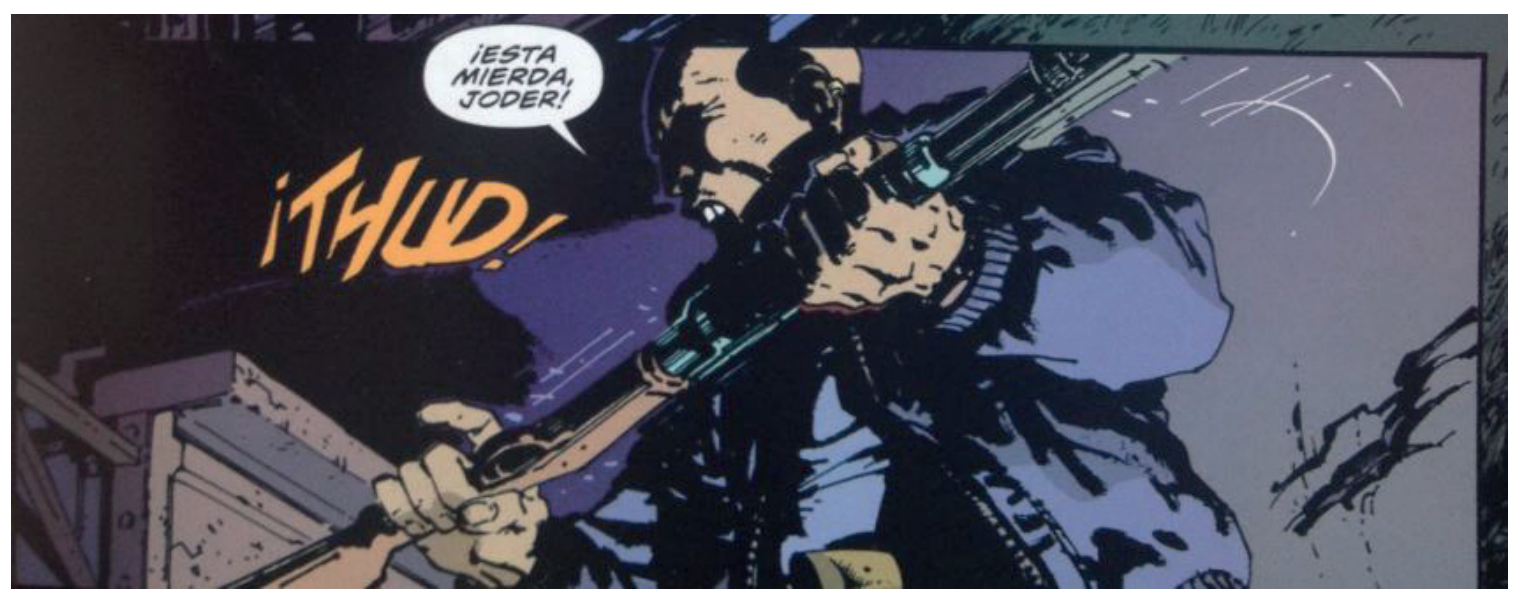

FIG. 2. Aaron, J. y GuÉra, R. M. Scalped: Libro uno, trad. G. Ruiz Carreras. Barcelona, El Catálogo del Cómic Ediciones, 2016, p. 33.

publicitarios, pancartas de protesta o de recortes de periódicos, mientras que en la versión de 2008 no se traduce el texto de los insertos, ni siquiera se reproduce en cuadros de texto añadidos al dibujo. Las FIG. 3 y 4 muestran esta discrepancia de criterios.

La traducción de Paletos cabrones se inscribe en la línea del trabajo de Ruiz Carreras, ya que en la versión de García de Isusi sí se traduce la mayoría de los insertos, caso de los carteles de la carretera y de las pintadas vandálicas en casa del protagonista (FIG. 5), pero no las onomatopeyas que indican disparos (blam), ladridos (ark) o hachazos (chok). No obstante, la no traducción de uno de los insertos conlleva la omisión de la versión sureña de la empresa de transportes y mudanzas You Haul, que en Paletos cabrones queda reflejada según la variante regional del pronombre personal de la segunda persona del plural, y'all (contracción de you all), que la convierte en Y'all Haul (FIG. 6). Esta broma lingüística se pierde en la versión castellana. 


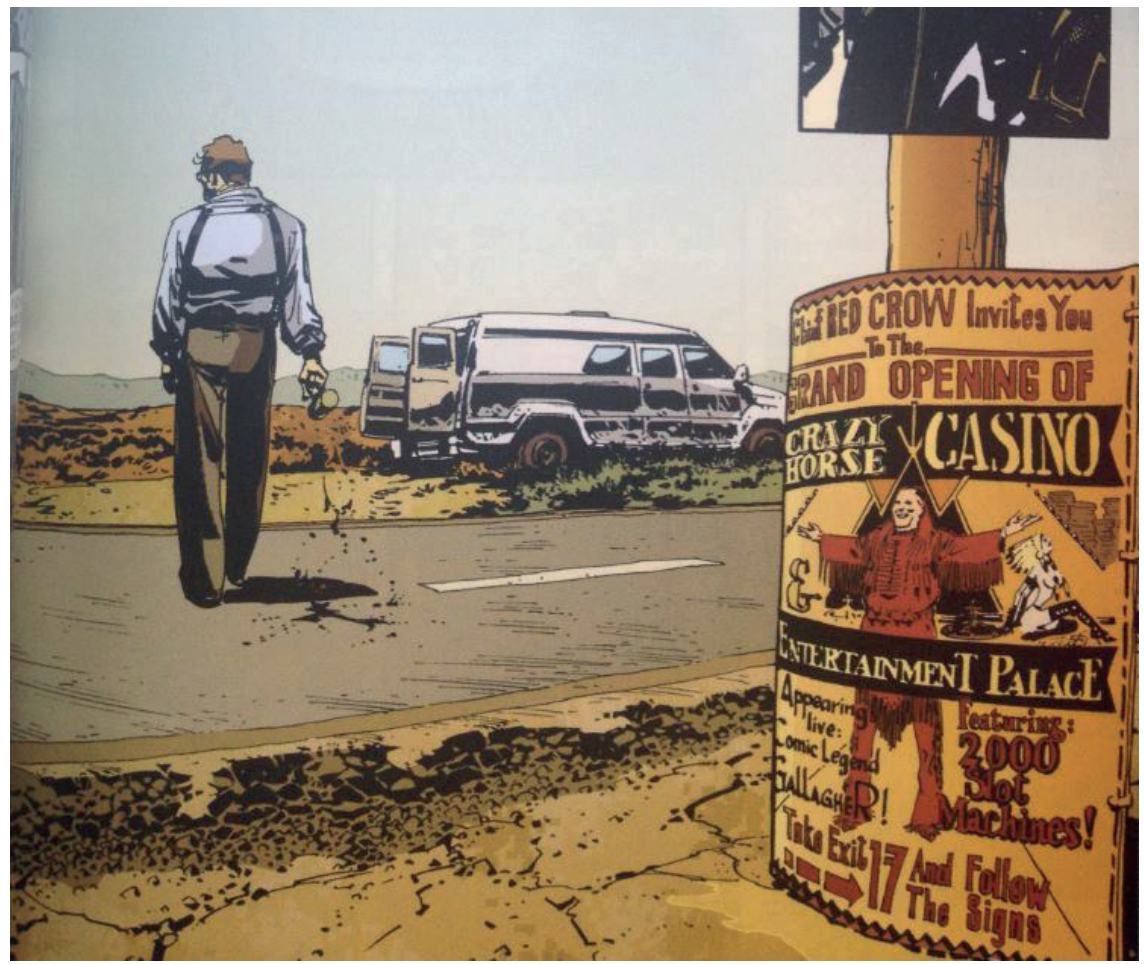

FIG. 3. Aaron, J. y Guéra, R. M. (2008), op. cit., p. 103.

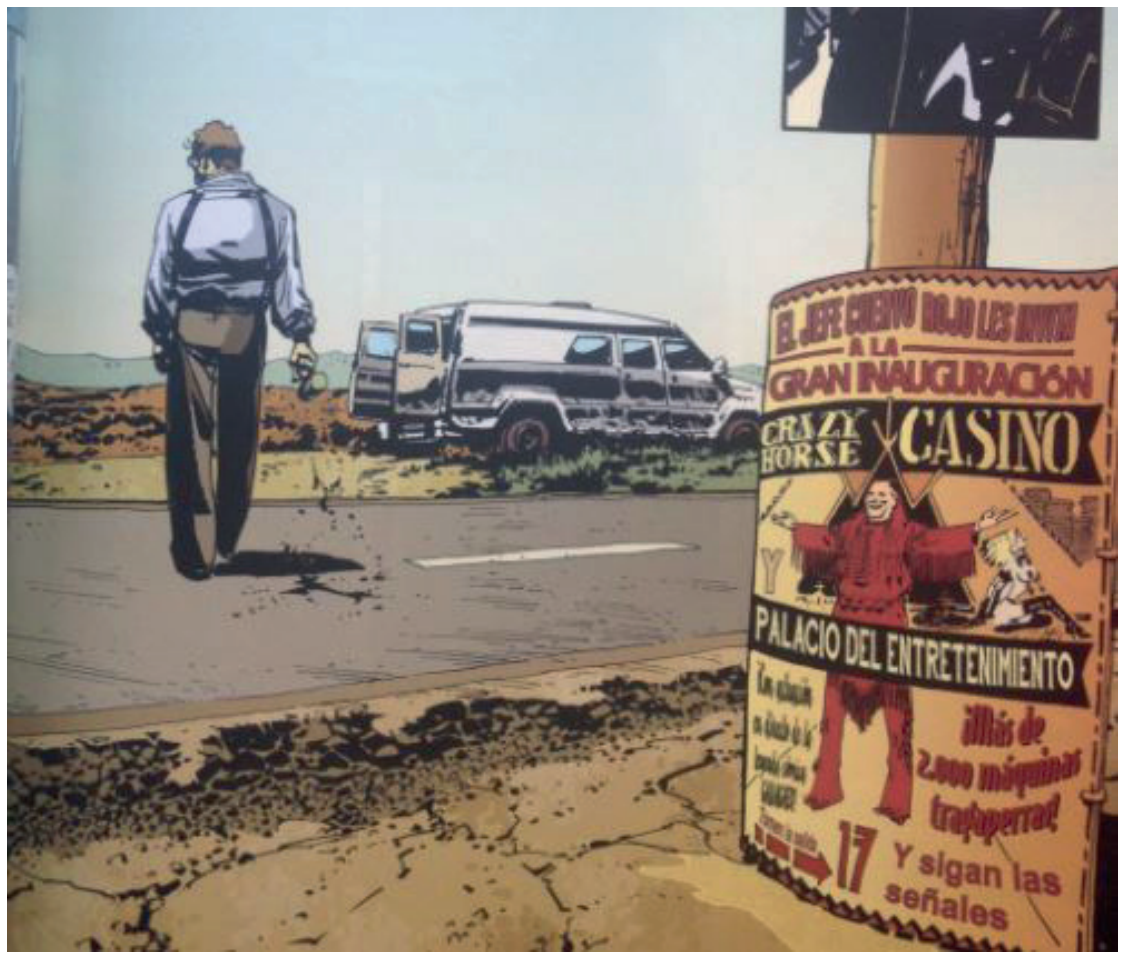

FIG. 4. Aaron, J. y Guéra, R. M. (2016), op. cit., p. 107. 
Igualmente, Quesada traduce los insertos dentro de los propios dibujos del cómic, por ejemplo en las señales de advertencia de la granja del protagonista, el letrero de Urgencias del hospital o la portada de la Biblia que hay en la mesilla de la habitación del motel de carretera en el que se refugia Ruben. La herencia de la ira es un cómic de escasas onomatopeyas, un recurso narrativo que logra transmitir aspereza y crudeza a la historia del último asesinato por encargo de Ira Rath. Las onomatopeyas aparecen en momentos puntuales,

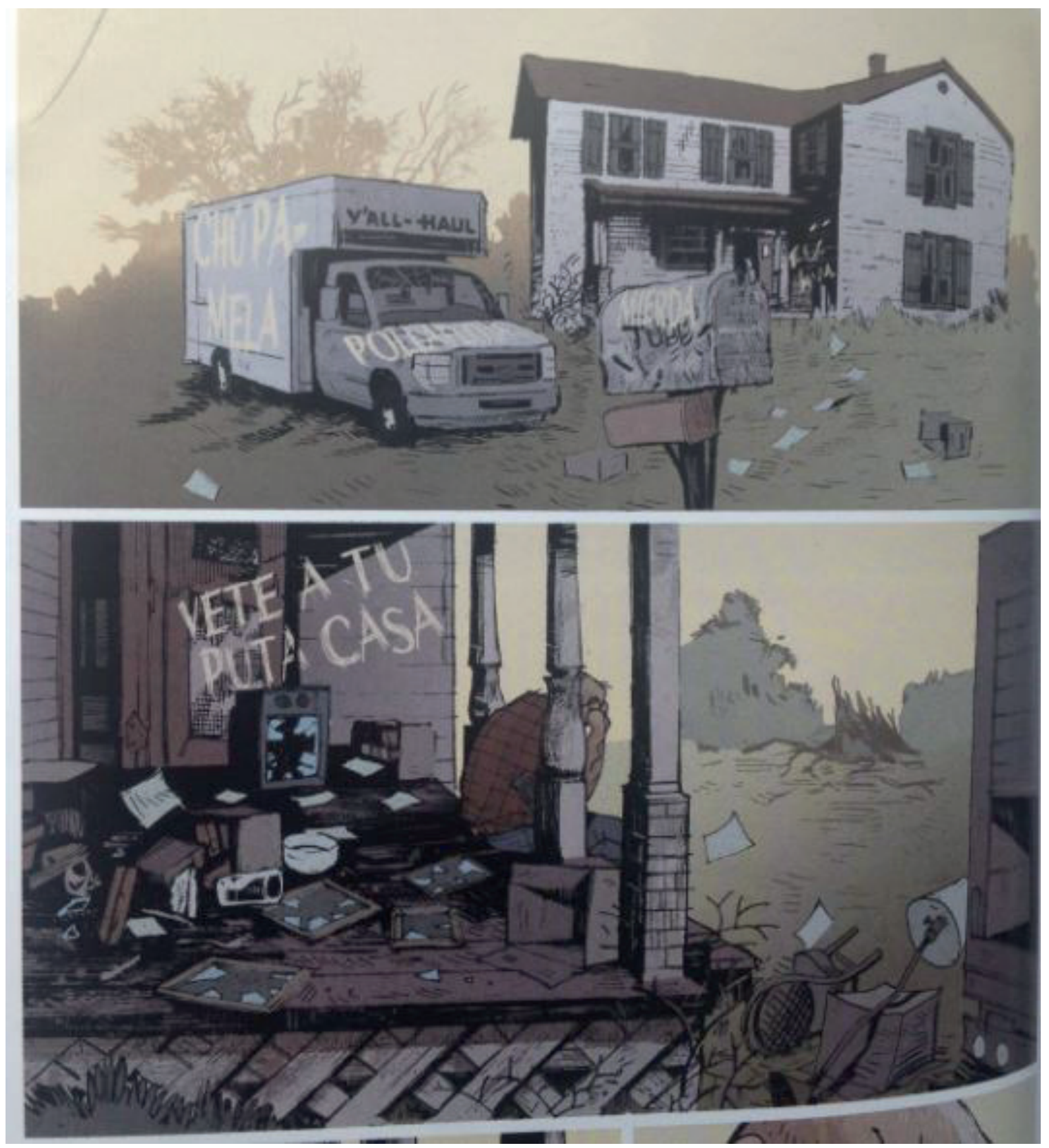

FIG. 5. Aaron, J. y Latour, J. Paletos cabrones: Aqui yace un hombre, trad. V. M. García de Isusi. Barcelona, Planeta, 2016, p. 84. 


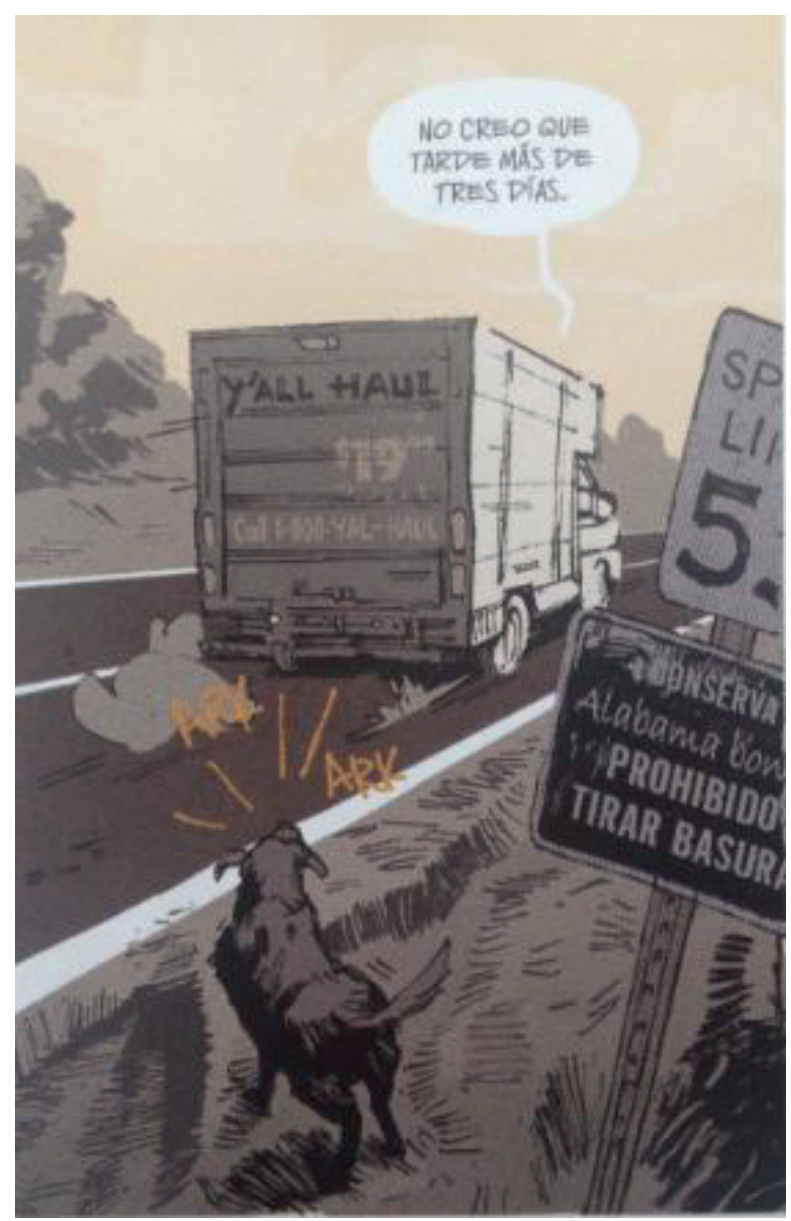

FIG. 6. Aaron, J. y Latour, J. Op. cit., p. 8.

por ejemplo cuando el protagonista dispara por primera vez y cuando su hijo decide defenderse y usar la pistola que le ha arrebatado a Ira, pero no están presentes en las secuencias de tiroteos violentos, ni siquiera en el enfrentamiento final contra la banda criminal de los Polk, la familia que contrata a Ira de asesino a sueldo. Como sucediera con las versiones en castellano de Scalped y Paletos cabrones, las onomatopeyas de La herencia de la ira no se han alterado y mantienen la grafía original inglesa, caso de blam! para los disparos.

\subsection{La intertextualidad}

Hurtado Albir define esta cualidad como la «dependencia de un texto respecto a otro; condición necesaria para la inteligibilidad de los textos», ${ }^{27}$ dado que no hay texto que brote exclusivamente de la nada, sino que depende de otros. La relación entre dos o más textos puede ser de dos tipos: directa u horizontal, cuando un texto se refiere a otro de forma explícita, caso de las citas; e indirecta o vertical, en la que la referencia es velada e implícita y

${ }_{27}$ Hurtado Albir, A. Traducción y traductología: Introducción a la traductología. Madrid, Cátedra, 2001, p. 638. 
puede consistir en alusiones a nombres propios, frases hechas de determinados personajes, canciones, citas literarias, eslóganes publicitarios, etc. Es tarea del traductor, por tanto, identificar las alusiones intertextuales del texto en la lengua de origen, decidir si las omite o las vierte a la lengua meta y, en este último caso, qué estrategias sigue.

En el segundo apartado de este artículo se ha hablado de algunos de los referentes literarios de los cómics negrocriminales de Aaron, de los que bebe en estilo y temática. Ahora bien, los diálogos ágiles y descreídos de estas tres obras presentan alusiones intertextuales a personajes y elementos de la cultura popular que los enriquecen. Por ejemplo, en Scalped, Dashiell Caballo Terco acaba de conversar con su interés amoroso, Carol Ellroy, cuando el delincuente que va en el asiento trasero de su coche patrulla y ha observado la escena llama al protagonista, en tono jocoso, «Rico Suave» (FIG. 7). Se trata de una referencia al protagonista de la canción homónima del rapero Gerardo, que trata del estereotipo del amante latino y gozó de bastante popularidad a principios de los años noventa. Esta alusión se omite en la traducción de García, pero en la de Ruiz Carreras se compensa con un equivalente funcional que no precisa el referente pero recoge su significado, cuando el delincuente llama «pichabrava» a Dashiell (FIG. 8). De forma análoga, cuando, en el número 4, Carol insulta

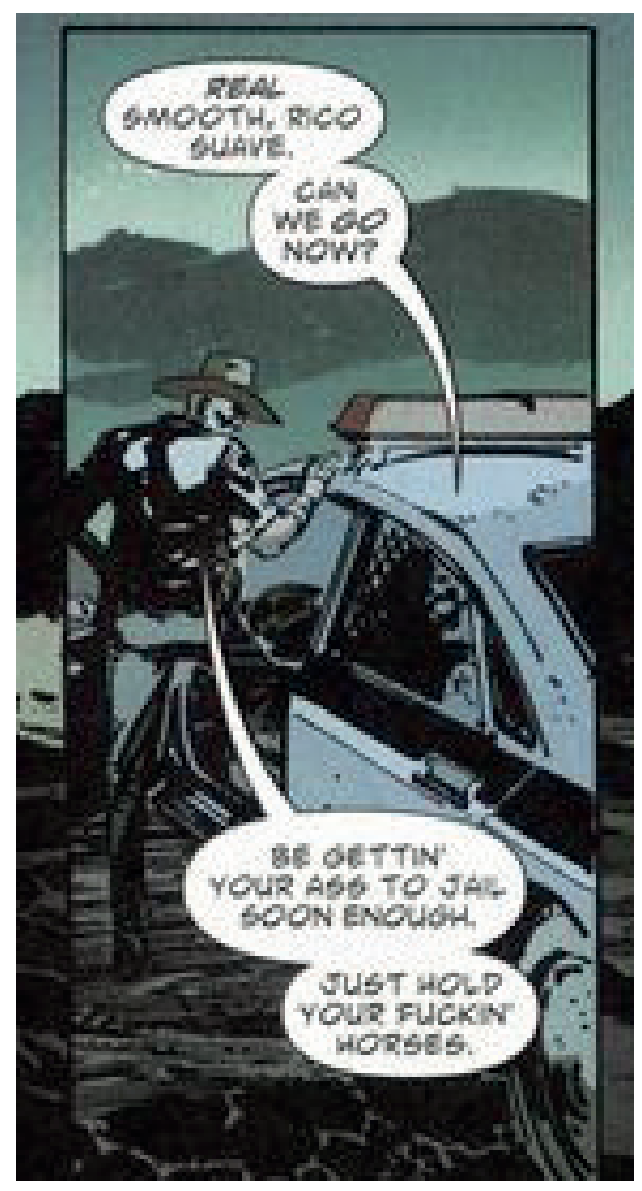

FIG. 7. Aaron, J. y Guéra, R. M. Scalped, n.o 3. Nueva York, DC Comics, 2007, p. 18.

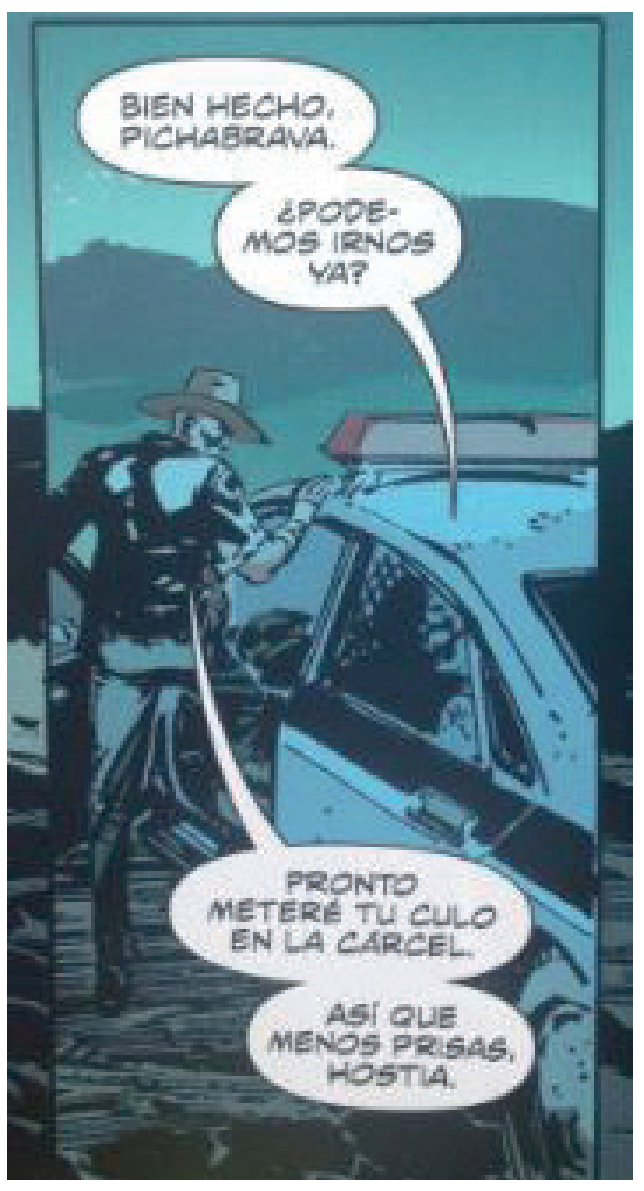

FIG. 8. Aaron, J. y GuÉra, R. M. (2016), op. cit., p. 73. 
a uno de sus clientes y le llama «Beavis», en referencia a uno de los ingenuos protagonistas de la serie de la MTV Beavis and Butt-Head, la versión de 2008 lo sustituye por la cualidad que representa, de modo que pasa a llamarle «inocente», mientras que la traducción de 2016 mantiene el nombre del personaje, sin desarrollar ni especificar más la alusión. Las dos traducciones sí coinciden, en cambio, en la referencia intertextual a la violenta secuencia final del wéstern Grupo salvaje (1969), de Sam Peckinpah, cuando, en el capítulo 3 de Scalped, Dashiell se reúne con su jefe del FBI y este le reprende por su comportamiento temerario, pierde los nervios y le dice: «Dios. Por favor, dime que no has hecho un puto Grupo salvaje y te has cargado la puta tapadera con Cuervo Rojo». ${ }^{28}$

Como se ha mencionado en el segundo apartado, la familia Compson aparece en Paletos cabrones, lo cual sería un caso de intertextualidad indirecta a los protagonistas de la novela El ruido y la furia. Dado que en el cómic original no se dan más explicaciones al respecto y corresponde al lector establecer esta conexión, tampoco la traducción al español requiere desarrollar más la alusión, ni mucho menos añadir una nota explicativa acerca de quiénes son los Compson del Sur de Estados Unidos. Otra referencia indirecta que se ha traducido pero tampoco se ha explicitado se puede ver en el cuarto capítulo, cuando, antes de su enfrentamiento final con el entrenador Boss, Earl Tubb apela al civismo de los habitantes del Condado de Craw, a quienes llama «buena gente de campo». ${ }^{29}$ Así, alude directamente al relato del mismo título de Flannery O'Connor, ${ }^{30}$ en el que Joy, una joven intelectual de Georgia, trata de seducir a un apuesto y en apariencia bonachón vendedor ambulante de biblias que termina por engañarla y robarle.

Finalmente, en las traducciones de estos cómics se da un caso curioso de intertextualidad directa añadida, es decir, que no estaba presente en el original pero sí en la lengua meta. En el desenlace del segundo número de Scalped, el jefe Caído acusa a Dashiell de buscar con desesperación una muerte gloriosa y ruidosa, «somewhere out there there is a blaze of fuckin' glory... with your name written all over it», que Ruiz Carreras reelabora como «solo podrás morir de una puta manera... y será con las botas puestas». ${ }^{31}$ Estas mismas expresiones son las que emplea Lizzie para dirigirse a su suegro en el cierre de El legado de la ira, cuando le espeta "Quería morir como un Rath, con las botas puestas». ${ }^{32} \mathrm{Al}$ traducir go out in a blaze of glory por «morir con las botas puestas», ambos traductores introducen una cita intertextual a la película de Raoul Walsh Murieron con las botas puestas (1941), centrada en la figura del coronel Custer, quien murió luchando contra los indios en la batalla de Little Big Horn (1876). No es casualidad que Scalped aborde este hecho histórico, que recrea en las primeras páginas del número 25 .

28 Aaron, J. y Guéra, R. M. (2016), op. cit., p. 64.

29 Aaron, J. y Latour, J. Paletos cabrones: Aqui yace un hombre, trad. V. M. García de Isusi. Barcelona, Planeta, 2016, p. 91.

30 O’Connor, F. Op. cit.

31 Aaron, J. y Guéra, R. M. (2016), op. cit., p. 54.

32 Aaron, J. y Garney, R. La herencia de la ira, trad. G. Quesada. Gerona, Panini Cómics, 2016, p. 120. 


\subsection{Los títulos}

Si las estrategias para la traducción de la intertextualidad del apartado anterior tenían puntos en común, no sucede lo mismo con los títulos de estos tres cómics, que obedecen a estrategias traductoras dispares. Puesto que el nombre de una obra y su contenido suelen estar estrechamente relacionados, el modo en que se traducen los títulos resulta fundamental en un primer acercamiento a la obra. La versión en la lengua meta de los títulos no solo ha de respetar la intención del original, sino que también ha de resultar atractiva para los lectores potenciales.

En el campo de la traducción de los títulos de las películas, que tantas traducciones excéntricas ha propiciado, se distinguen dos estrategias, ${ }^{33}$ que cuentan a su vez con varias subcategorías y pueden aplicarse a la traducción de los títulos de novelas y cómics. Son el respeto por el título original frente al distanciamiento absoluto. Dentro de la primera categoría se encuentran la transliteración, que es la copia exacta de la forma original; la traducción literal, que reproduce la forma y traduce el contenido del título de partida; y la explicación, que consiste en añadir un subtítulo que no estaba presente y aclara el significado. A su vez, las estrategias de distanciamiento pueden subdividirse en la adaptación, que busca facilitar la comprensión del título mediante un equivalente cultural en la lengua de llegada; y la creación de un título completamente nuevo que debería basarse en el argumento de la obra.

Scalped, como se ha indicado en el apartado 2 , hace referencia a la práctica, asociada a los nativos americanos, de arrancar la cabellera a sus enemigos. Es el participio pasado del verbo to scalp, por lo que una traducción literal del título sería «sin cabellera» o «con la cabellera arrancada». En este caso, ambas versiones españolas han optado por la transliteración para mantener el título original en inglés, sin traducirlo. Con Paletos cabrones pasa lo contrario, pues el Southern Bastards original, que vendría a significar, literalmente, «cabrones sureños», queda a medio camino entre la adaptación y la creación de un título nuevo que mantiene el improperio y reformula la alusión a un área geográfica y cultural concreta de Estados Unidos en el calificativo destinado a las personas rústicas de pocos modales, los «paletos». Por su parte, el título de la miniserie de Icon se ha adaptado al pasar de Men of Wrath a $\mathrm{La}$ herencia de la ira, si bien cabe subrayar que se ha perdido un matiz de la trama del cómic: que la herencia de violencia a la que se refiere se transmite de padres a hijos varones y no es hasta la llegada de Lizzie y la hija de Ruben en el último capítulo cuando surge la posibilidad de ponerle fin.

\subsection{El habla dialectal}

Como se señalaba al final del segundo apartado, estos tres cómics participan de cierto costumbrismo a la hora de retratar las comunidades raciales y grupos sociales a los que pertenecen

33 Yin, L. «On the translation of English movie titles», en Asian Social Sciences, vol. 5, n. 3 (2009), pp. 171-173. 


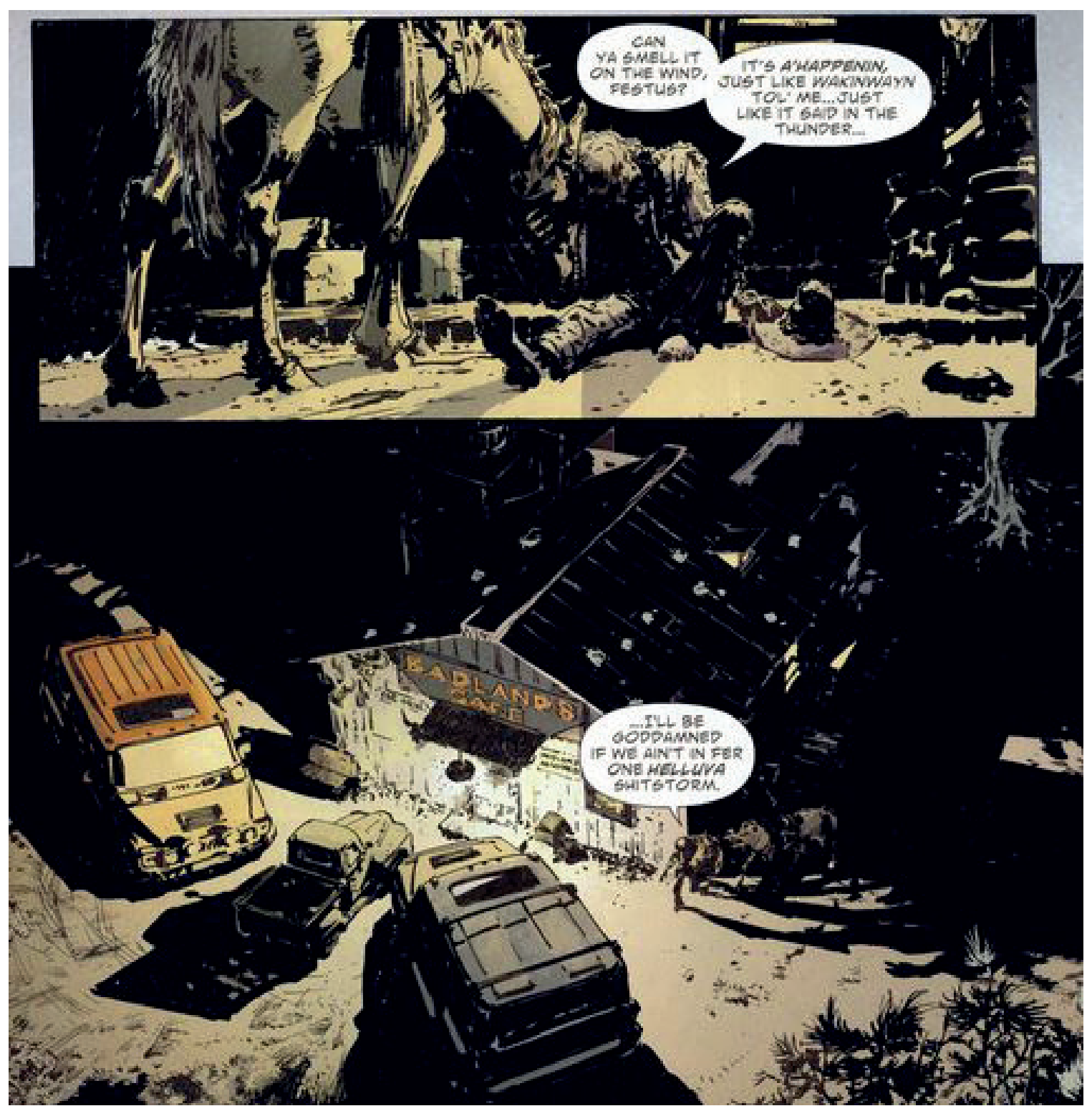

FIG. 9. Aaron, J. y Guéra, R. M. Scalped, n.o 1.

Nueva York, DC Comics, 2007, p. 1.

los protagonistas; la reserva india de Dakota del Sur en el caso de Scalped y los pueblos de Alabama en Paletos cabrones y La herencia de la ira. El habla de estas comunidades se refleja en la grafía de los diálogos que escribe Aaron, en los que los apócopes y las contracciones plasman una pronunciación relajada que denota la poca educación del hablante, como puede apreciarse en el caso de Catcher, un viejo chamán indio que malvive en las condiciones de pobreza extrema de la reserva Prairie Rose (FIG. 9). Es más, hay determinadas escenas de tensión en las que los personajes de Scalped hablan en lakota y no se incluye explicación alguna de qué dicen en el texto original, ni siquiera en una nota al pie o en un cuadro de texto, como puede verse a continuación en la FIG. 10. 


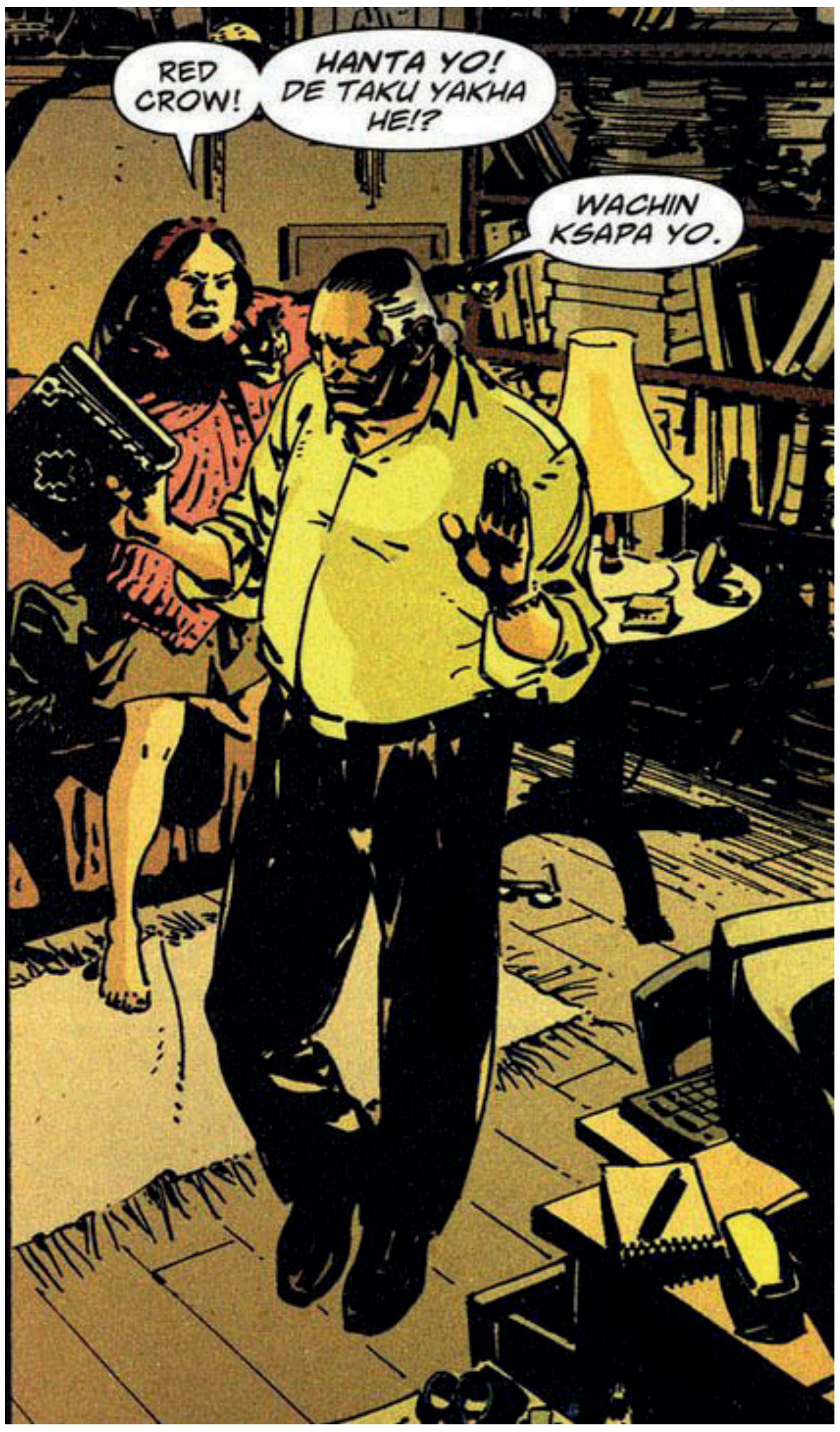

FIG. 10. Aaron, J. y Guéra, R. M. Scalped, n. ${ }^{\circ}$.

Nueva York, DC Comics, 2007, p. 4. 
La oralidad fingida de Paletos cabrones también propicia que las alteraciones ortográficas reproduzcan el habla rural del Condado de Craw y sean más pronunciadas en personajes como Esaw, el hijo del predicador y matón del entrenador Boss. La FIG. 11 es un ejemplo de los apócopes, fruto de una pronunciación relajada, que pueblan sus bocadillos, al igual que pasa en los de Dusty, el viejo conocido de Tubb. De forma similar, estas marcas dialectales del habla en La herencia de la ira diferencian a los personajes más brutos y menos educados del mundo rural que retrata, como en el ejemplo de la FIG. 12, en el que el jefe de la banda de Polk da instrucciones a sus matones y les indica en qué consiste su próximo golpe.

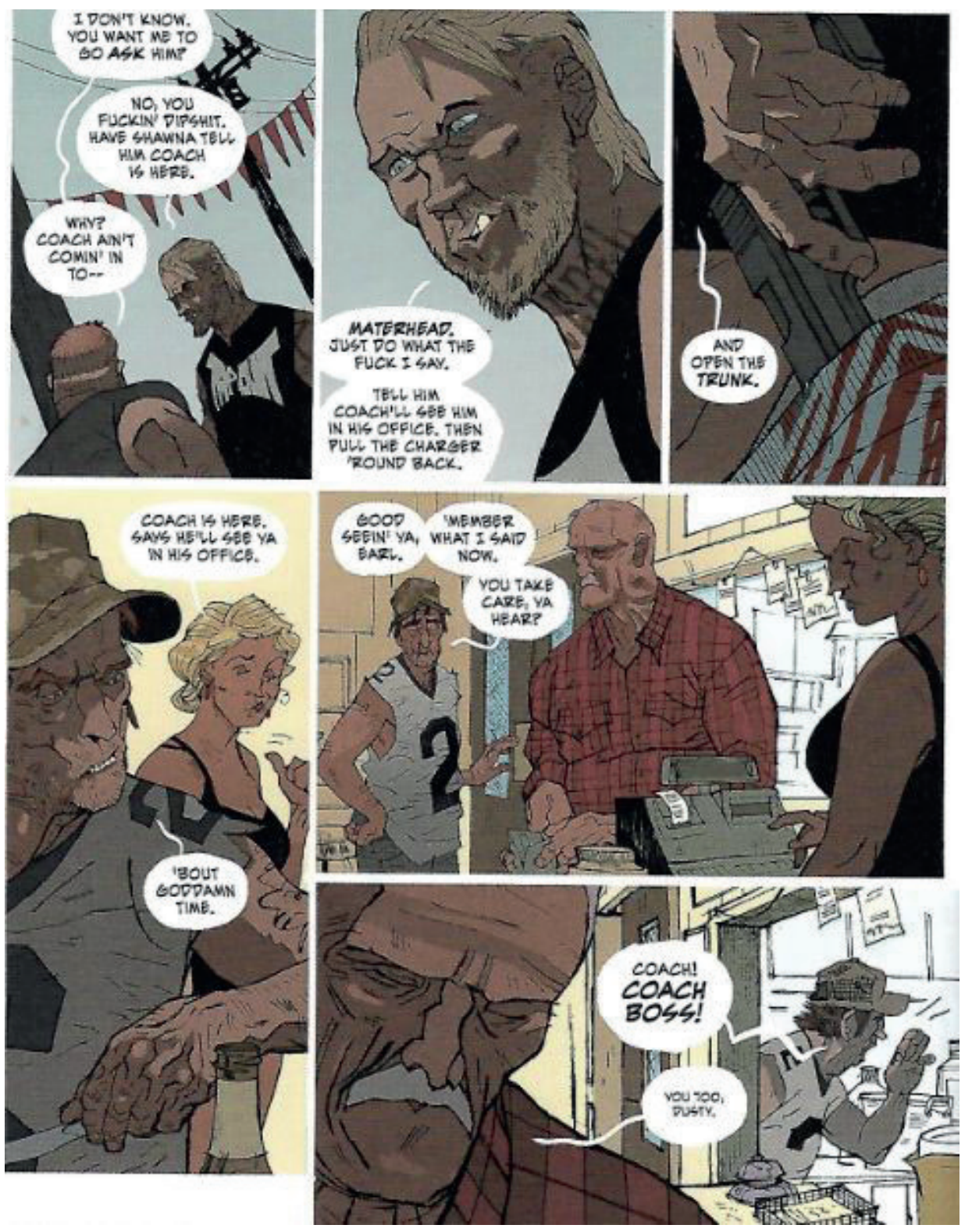

FIG. 11. Aaron, J. y Latour, J. Southern Bastards: Here Was a Man. Berkeley, CA, Image Comics, 2014, p. 22. 


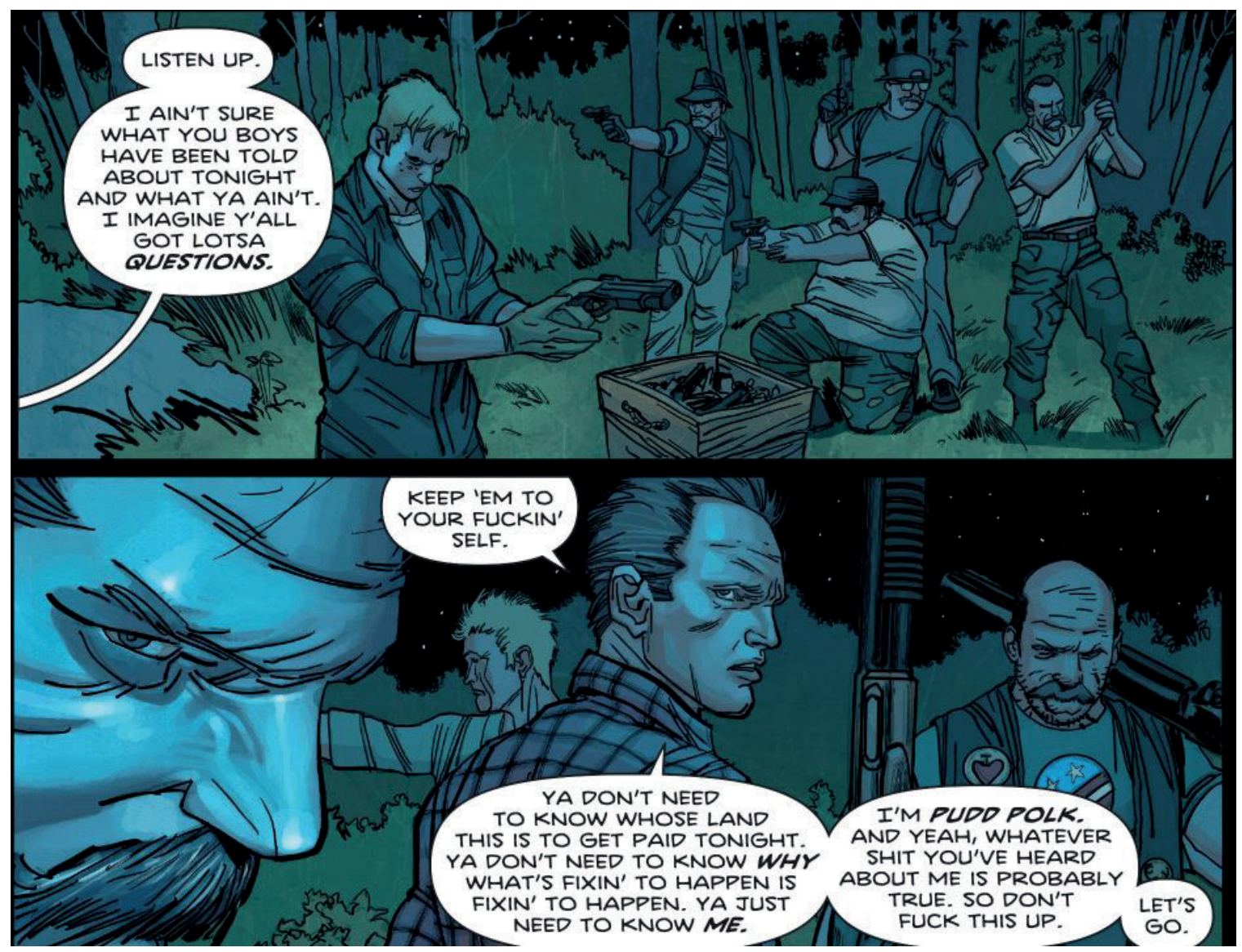

FIG. 12. Aaron, J. y Garney, R. Men of Wrath, n. ${ }^{\circ}$ 2. Nueva York, Marvel Comics, 2014, p. 11.

Ahora bien, tras estos ejemplos, surge el problema de qué estrategias se pueden aplicar para traducir el dialecto y si es posible reflejar estas marcas del habla del texto original en la lengua meta. Hurtado Albir habla de las variedades de la lengua que tienen que ver tanto con la persona que las utiliza como con el contexto de su uso particular. ${ }^{34}$ Esta autora distingue entre registros, que son los distintos usos de la lengua en relación con el área profesional, el nivel de formalidad o con si los textos son orales o escritos; y dialectos, que son las variedades lingüísticas que dependen de variables como el tiempo (dialecto temporal), el espacio (dialecto geográfico) o la clase social (dialecto social). De este modo, mientras que los dialectos temporales son variedades diacrónicas de la lengua, los geográficos y sociales se pueden considerar variedades diatópicas que se alejan de la lengua estándar de un determinado período. El dialecto literario puede definirse como el intento de mostrar en la página impresa el habla de un grupo étnico, racial o regional concreto por medio de faltas de ortografía, omisiones, apóstrofos y cambios sintácticos. La función del dialecto literario depende de las convenciones y los estereotipos que se relacionen con sus rasgos, pues puede ser objeto de burla o una marca de identidad.

${ }^{34}$ Hurtado Albir, A. Op. cit., p. 544. 
López García respalda estas consideraciones y apunta, en relación con las variedades dialectales, que «dejar de traducir esos efectos expresivos de la lengua de origen priva al lector de una información cardinal para comprender la obra que lee». ${ }^{35}$ Por tanto, hay que «hacer llegar al lector la peculiar desviación expresiva de la norma que ofrece el dialecto», ${ }^{36}$ es decir, realizar un ejercicio de coherencia y trasladar las connotaciones asociadas a una variedad en particular y «explicar por qué razones [el traductor] ha elegido un determinado método de traducción». ${ }^{37}$ Sáenz matiza que el problema de la traducción del dialecto sí tiene muchas soluciones, mas todas ellas resultan insatisfactorias. ${ }^{38}$

La mentada Rabadán también dedica un capítulo a la traducción del dialecto en el que, en general, adopta una postura bastante escéptica. ${ }^{39}$ Para ella, los dialectos representan desviaciones de la norma culta, que se corresponde con el habla de las clases sociales más favorecidas. Sostiene que los textos que están completamente escritos en dialecto nunca deben traducirse a otro dialecto, sino a la variedad estándar de la lengua de llegada, dado su carácter uniforme, si bien se pueden añadir coletillas del tipo «dijo en dialecto», estrategia que funcionaría en novela, pero no en los bocadillos del cómic. Si el mantenimiento del sentido depende de los rasgos dialectales, se debe elegir en la lengua meta un dialecto que pueda evocar las mismas connotaciones que el original y cumpla las mismas funciones de caracterización geográfica y social. En última instancia, serán los lectores de la lengua de llegada quienes determinarán si la traducción del dialecto es aceptable. Hatim y Mason ${ }^{40}$ ponen de manifiesto el problema insoslayable de qué dialecto de la lengua de llegada hay que usar en la traducción, puesto que, si se traduce por la norma culta estándar de la lengua meta, se pierden las connotaciones del texto fuente; mientras que si se traduce un dialecto por otro existe el riesgo de crear efectos distintos de los originarios. Subrayan los problemas de comprensión, incluso para los lectores de los textos de la lengua fuente, que suponen los dialectos temporales, para los cuales proponen dos opciones: la traducción hacia una variante arcaica de la lengua de llegada o hacia la variante estándar y contemporánea. En cuanto a los dialectos sociales y geográficos, Hatim y Mason subrayan su función sociocultural y la relevancia de las implicaciones políticas e ideológicas que puedan conllevar, pues los dialectos son una consecuencia de la estratificación social de la comunidad lingüística. Inciden en la necesidad de traducirlos y de respetar la carga social del original, pero no dicen cómo hacerlo, si bien apuntan que no es necesario seleccionar una variedad regional en concreto, sino que se puede recurrir a modificaciones del estándar, por ejemplo a variar la gramática y el léxico de la lengua de llegada de forma deliberada.

35 López García, D. Sobre la imposibilidad de la traducción. Cuenca, Universidad de Castilla-La Mancha, 1991, p. 93.

36 Idem.

37 Ibid., pp. 94-95.

38 SÁenz, M. «Dialectos dilectos», en El Trujamán, revista diaria de traducción, 3 noviembre 2000.Disponible en http://crc.cervantes.es/trujaman/anteriores/noviembre 00/03112000.htm.

39 Rabadán, R. Op. cit., pp. 79-109.

${ }^{40}$ Натіm, B. y Mason, I. Teoría de la traducción: Una aproximación al discurso, trad. S. Peña. Barcelona, Ariel, 1995, pp. 55-64. 
En esta misma línea, Tello Fons defiende que los traductores deben tener la posibilidad de llevar a cabo la traducción de la variación lingüística y de elegir entre un abanico de opciones según la función del dialecto en el texto de origen. Considera la variación de la norma lingǘstica de la lengua meta como un vehículo para dar credibilidad a un dialecto que en el original reflejaba el habla propia de un lugar, grupo social o personaje determinado. ${ }^{41}$ Asimismo, analiza las funciones compatibles que puede tener la presencia del dialecto en una obra literaria: ${ }^{42}$ la función mimética, que refleja la realidad del habla de una comunidad lingüística determinada; $y$ la función simbólica, en la que el dialecto actúa como una herramienta para establecer oposiciones entre personajes, proyecta una ideología determinada y busca mover los sentimientos de los lectores hacia los personajes. Al dotar a un personaje de un habla dialectal, el autor lo destaca. La autora también subraya que las marcas dialectales requieren un esfuerzo extra de comprensión por parte de los lectores y que se pueden combinar varios, aunque uno adquiera más protagonismo; por ejemplo, un dialecto geográfico puede apuntar hacia cierta condición social. Respecto a las estrategias que se pueden emplear para la traducción de las variedades dialectales, Tello Fons se plantea, en primer lugar, optar por un texto con marcas, que transgreda la norma lingüística de la lengua meta en alguno de sus niveles (ortográfico, gramatical o léxico) o por uno sin marcas, estandarizado. En segundo lugar, existe la posibilidad de elegir entre un dialecto en concreto de la lengua de llegada para la traducción y una configuración artificial que mezcle rasgos de varios dialectos, sin que recuerde a ninguno específico.

A propósito de este tema particular, Paradela López rescata las soluciones propuestas por Tello Fons y hace hincapié en que no se pierdan las connotaciones del original. ${ }^{43}$ Distingue entre el anatopismo, que se corresponde con la segunda opción de Tello Fons y hace creer a los lectores, por ejemplo, que los personajes son gallegos o andaluces por su forma de hablar, aunque la obra esté ambientada en otro lugar; y el atopismo, que consiste en crear dialectos que no se correspondan con ningún lugar concreto, si bien su presencia hace que el lector note una diferencia en el habla.

$\mathrm{Si}$, tras estas consideraciones traductológicas, se observan las traducciones correspondientes a las FIG. 9, 11 y 12, se comprueba que las marcas dialectales de los cómics originales se han neutralizado en sus respectivas traducciones, en las que se ha optado por un registro estándar de la lengua meta (FIG. 13, 14 y 15). Incluso en el caso de las retraducciones de Scalped, ninguna de las dos ha optado por una estrategia diferente a la estandarización del habla marcada. Esto puede deberse a que prime la búsqueda de la aceptación del texto meta por parte de los lectores, por lo que se decide no transgredir las normas ortotipográficas. Lo que no se ha traducido y se ha dejado como en el texto original son los fragmentos en lakota de Scalped, que permanecen en cursiva en ambas versiones en castellano.

${ }^{41}$ Tello Fons, I. «Traducción de la variación lingüística: Una visión diacrónica», en Hikma, n.o 11, (2012), pp. 133-159.

42 Idem.

43 Paradela López, D. «Traducir dialectos», en El Trujamán: Revista diaria de traducción, 29 julio, 12 septiembre y 6 octubre 2014. Disponible en https://goo.gl/T6CXGO. 


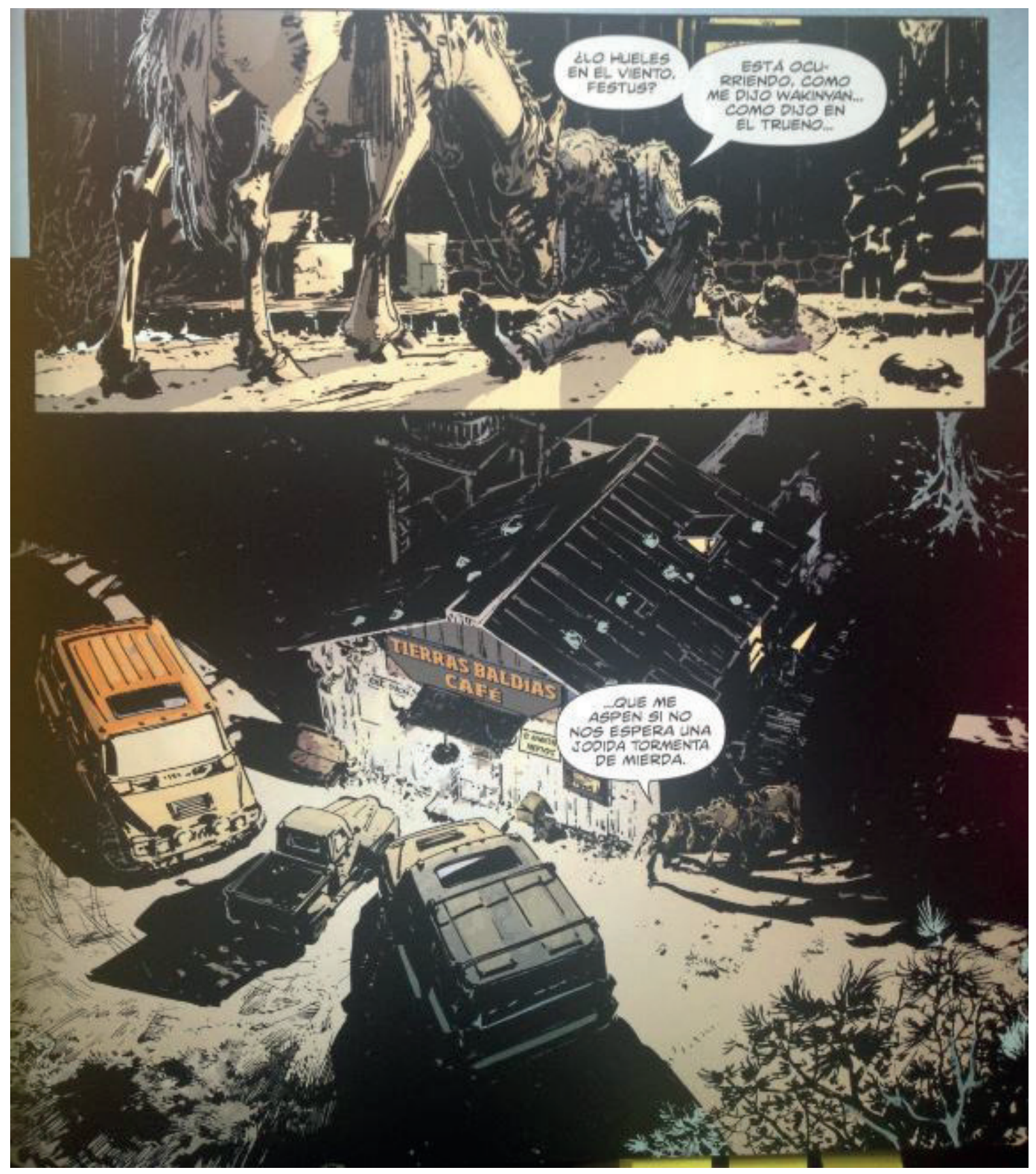

FIG. 13. Aaron, J. y Guéra, R. M. (2016), op. cit., p. 9.

\section{Conclusiones}

Este artículo se proponía estudiar las características del lenguaje de los cómics del guionista Jason Aaron que se enmarcan en el género negro y sus respectivas traducciones al español, caso de Scalped, Paletos cabrones y La herencia de la ira. En primer lugar, se ha precisado qué obras sirven de base para el trabajo de Aaron, para lo cual se ha señalado la influencia del 

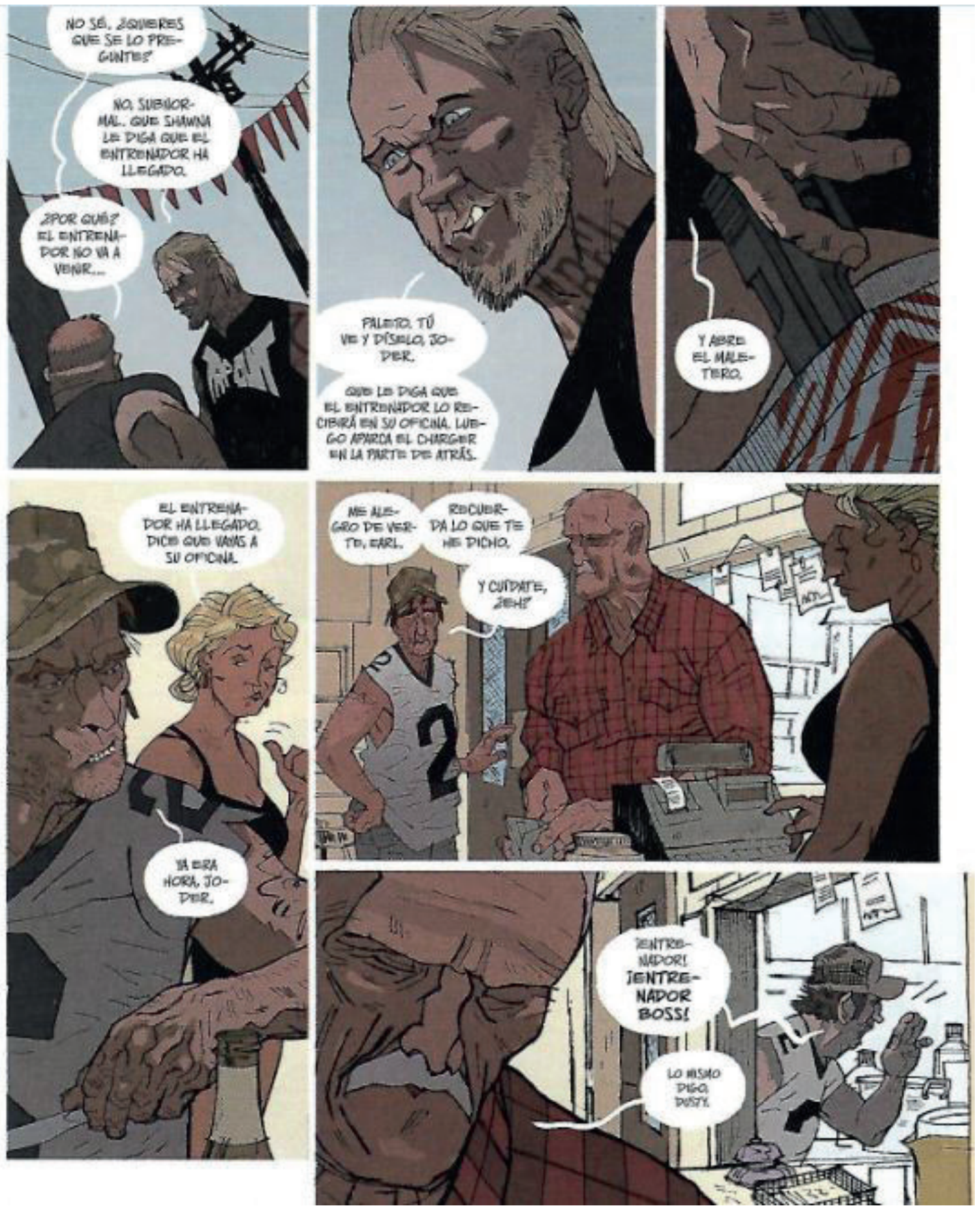

FIG. 14. Aaron, J. y Latour, J. Op. cit., p. 22.

género negrocriminal o hard-boiled estadounidense, al que pertenece la novela Cosecha roja; del gótico sureño que representan autores como Faulkner y O'Connor y del violento wéstern crepuscular de McCarthy. 


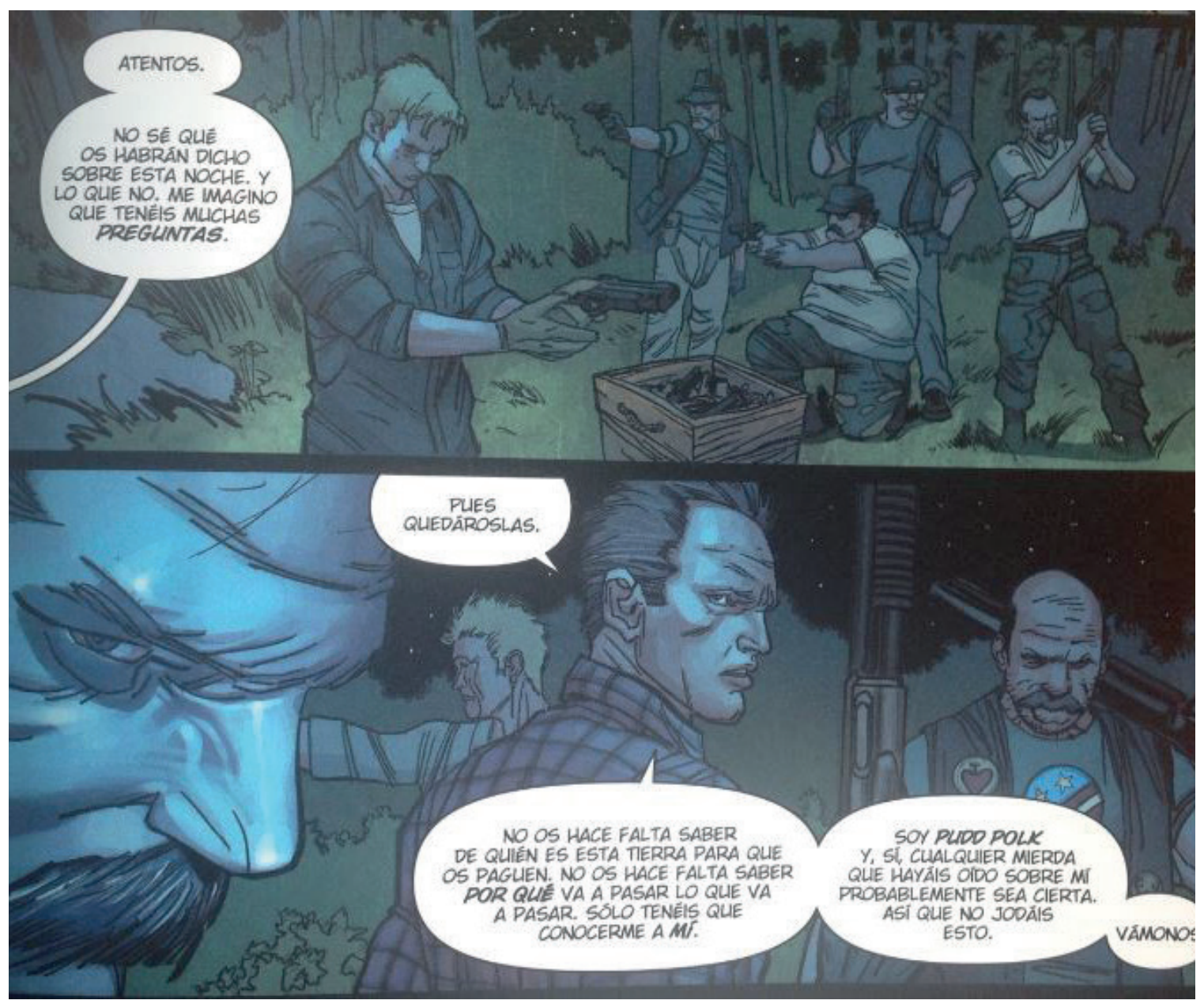

FIG. 15. Aaron, J. y Garney, R. La herencia de la ira, trad. G. Quesada. Gerona, Panini Cómics, 2016, p. 35.

A continuación, la sección central de este estudio ha repasado ciertas consideraciones traductológicas vinculadas a la traducción del cómic, que está subordinada a las limitaciones físicas que impone el medio y al requisito de manipular los dibujos para traducir las onomatopeyas y los insertos. Tanto en las retraducciones de Scalped como en las versiones en castellano de Paletos cabrones y La herencia de la ira, se ha comprobado que no se traducen las onomatopeyas (si bien se les añade el signo de exclamación de apertura), mientras que los textos de los insertos sí se reemplazan por sus correspondientes traducciones a la lengua meta, con la salvedad de la primera traducción de Scalped de García, en la que no se alteraban y permanecían en inglés. A continuación, se han examinado las referencias intertextuales de estos tres cómics, directas e indirectas, y la alusión que se ha añadido al wéstern de Raoul Walsh en los textos meta. Asimismo, se han analizado las estrategias empleadas para traducir los títulos: mientras que Scalped se translitera y no se traduce, Paletos cabrones y La herencia de la ira son el resultado de adaptar los originales, con las consiguientes pérdidas de matices relacionados con la localización y la trama del cómic, respectivamente. 
El último punto se ha dedicado a la problemática de la traducción del dialecto, ya que las tres obras presentan, en los diálogos, ejemplos de habla marcada con pronunciaciones relajadas propias de los ambientes rurales en los que transcurre la acción. Tras un repaso de las observaciones de varios traductólogos y de la posibilidad de transgredir la norma para reflejar el habla marcada en la lengua meta, se ha comprobado que las cuatro traducciones objetos de estudio optan por suprimir cualquier rasgo dialectal a favor de un uso estandarizado de la lengua de llegada.

Este artículo puede servir de base a investigaciones futuras en las que se amplíe el corpus de estudio, tal vez hasta incluir la totalidad de los volúmenes que componen estas obras en vez del primero de cada una, y los aspectos lingüísticos que se analizarán en las traducciones publicadas en español, además de las onomatopeyas, los insertos, la intertextualidad, los títulos y el habla dialectal. Incluso se podría incorporar al estudio The Goddamned ${ }^{44}$ el cómic que Aaron y Guéra comenzaron a publicar en noviembre de 2015. Se trata de una recreación de la historia de Caín en la era inmediatamente anterior al diluvio universal, que de nuevo bebe del wéstern y mezcla las alusiones al Antiguo Testamento con el lenguaje contemporáneo, como se aprecia a continuación en la FIG. 16.

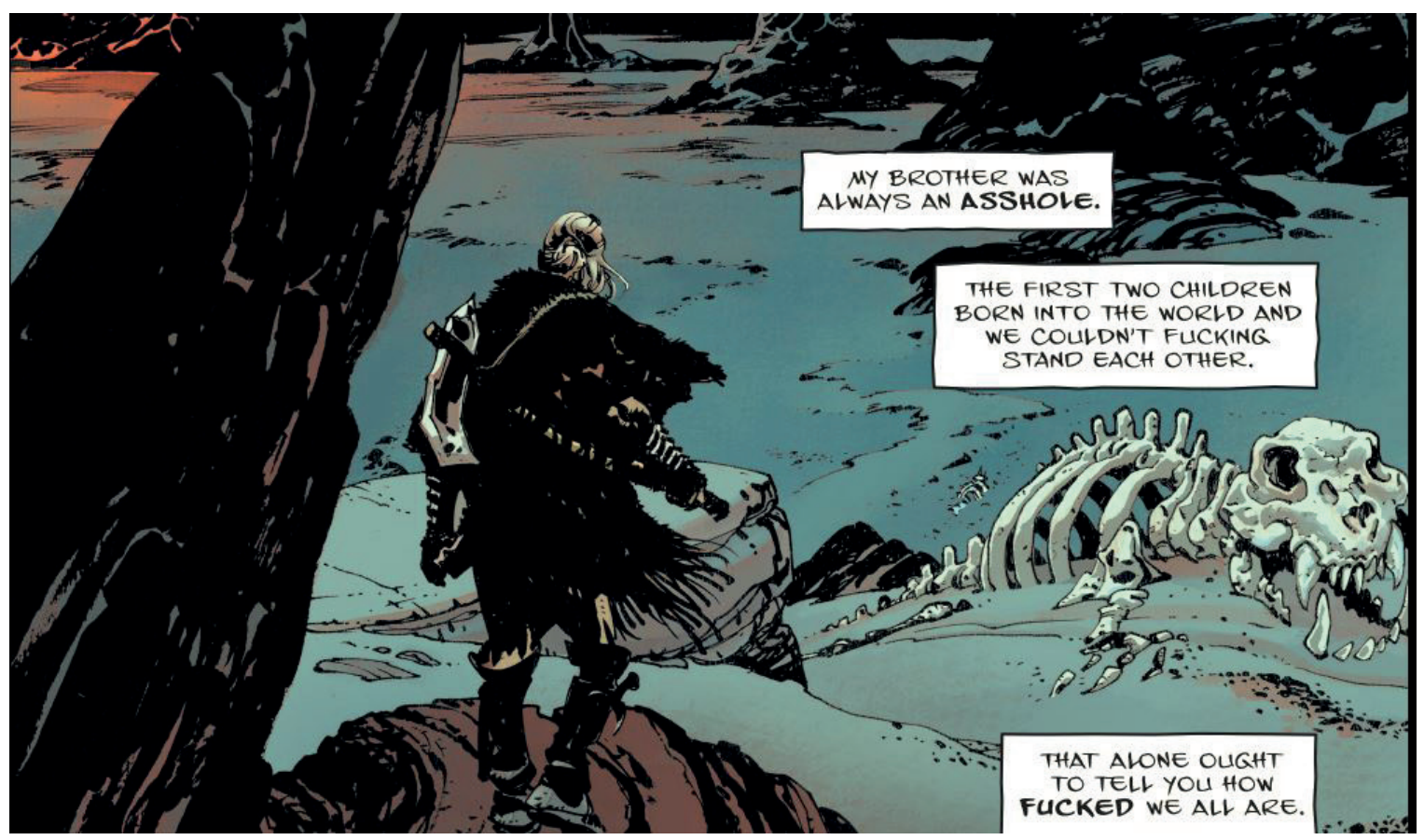

FIG. 16 Aaron, J.y Guéra, R. M. The Goddamned, n. ${ }^{\circ}$ 1. Berkeley, CA, Image Comics, 2015, p. 22 .

${ }^{44}$ Aaron, J. y Guéra, R. M. The Goddamned, n.o 1. Berkeley, CA, Image Comics, 2015. 


\section{BibLIOGRAFÍA}

Aaron, J.y Garney, R. Men of Wrath, n. o 1-5. Nueva York, Marvel Comics, 2014.

—La herencia de la ira, trad. G. Quesada. Gerona, Panini Cómics, 2016.

Aaron, J. y Guéra, R. M. Scalped, n. o 1-5. Nueva York, DC Comics, 2007.

-Scalped: Nación india, trad. B. García. Barcelona, Planeta, 2008.

—Scalped: Libro uno, trad. G. Ruiz Carreras. Barcelona, El Catálogo del Cómic Ediciones, 2016.

-The Goddamned, n. ${ }^{\circ}$ 1. Berkeley, CA, Image Comics, 2015.

Aaron, J. y Latour, J. Southern Bastards: Here Was a Man. Berkeley , CA, Image Comics, 2014.

-Paletos cabrones: Aquí yace un hombre, trad. V. M. García de Isusi. Barcelona, Planeta, 2016.

Faulkner, W. The Sound and the Fury. Londres, Vintage, 1995.

Gonzales, D. «Star Wars \#1 Is Already 2015`s Top Selling Comic», en Forbes, 13 enero 2015. Disponible en https://goo.g1/XXvQAd

Gubern, R. y Gasca, L. Diccionario de onomatopeyas del cómic. Madrid, Cátedra, 2008.

Hammetт, D. Cosecha roja, trad. F. Calleja. Madrid, Alianza, 1994.

Hatim, B. y Mason, I. Teoría de la traducción: Una aproximación al discurso, trad. S. Peña. Barcelona, Ariel, 1995.

Horsley, L. «American Hard-Boiled Crime Fiction», en Crimeculture, 2002. Disponible en https://goo.gl/mXF6rC

Hurtado Albir, A. Traducción y traductología: Introducción a la traductología. Madrid, Cátedra, 2001.

López García, D. Sobre la imposibilidad de la traducción. Cuenca, Universidad de Castilla-La Mancha, 1991.

McCarthy, C. Blood Meridian, or the Evening Redness in the West. Londres, Picador, 2010.

O’Connor, F. Cuentos completos, trad. M. Covián et al. Barcelona, Lumen, 2005.

Ortiz Gozalo, J. M. «La retraducción en el panorama de la literatura contemporánea», en Zaro Vera, J.J.y Ruiz Noguera, F. (eds.). Retraducir: una nueva mirada. La retraducción de textos literarios y audiovisuales. Málaga, Miguel Gómez, 2007, pp. 35-47. 
Paradela López, D. «Traducir dialectos», en El Trujamán: Revista diaria de traducción, 29 julio, 12 septiembre y 6 octubre 2014. Disponible en https://goo.gl/T6CXGO.

Peters, M. «From Scalped to Thief of Thieves: The most engrossing crime comics in history», en Salon, 3 agosto 2014. Disponible en https://goo.gl/xRlfx0.

Rabadán, R. Equivalencia y traducción: Problemática de la equivalencia translémica inglés-español. León, Universidad de León, 1991.

RAFERTY, B. «Paper Girls is the perfect comic for your "80s nostalgia trip», en Wired, 10 mayo 2016. Disponible en https://www.wired.com/2016/10/paper-girls-must-read/.

Rотн, P. La gran novela americana, trad. D. Paradela López. Barcelona, Contraediciones, 2015.

SÁEnz, M. «Dialectos dilectos», en El Trujamán, revista diaria de traducción, 3 noviembre 2000. Disponible en http://cvc.cervantes.es/trujaman/anteriores/noviembre 00/03112000.htm.

Tello Fons, I. «Traducción de la variación lingüística: Una visión diacrónica», en Hikma, n. ${ }^{\circ}$ 11, (2012), pp. 133-159.

YIN, L. «On the translation of English movie titles», en Asian Social Sciences, vol. 5, n. ${ }^{o} 3$ (2009), pp. 171-173.

Zaro Vera, J. J. «En torno al concepto de retraducción», en Zaro Vera, J. J. y Ruiz Noguera, F. (eds.). Retraducir: una nueva mirada. La retraducción de textos literarios y audiovisuales. Málaga, Miguel Gómez, 2007, pp. 21-34. 